\section{Specific Ionization of Gases by Soft Cosmic Rays, Residual Currents and Deep Water Measurements}

IT was shown by J. Juilfs and V. Masuch ${ }^{1}$ that the ionization by cosmic rays filtered at sea-level through $10 \mathrm{~cm}$. lead is proportional to the gas density in the measuring chamber. The same property was found by us to exist in the case of the soft cosmic rays in the upper layers of the troposphere. The measurements were made during a balloon ascent on May 14 between $6 \mathrm{~km}$. and $10 \mathrm{~km}$. Two similar spherical ionization chambers were used, one filled with nitrogen, the other with krypton containing about 5 per cent of xenon. The gases were kept under $16.5 \mathrm{~atm}$. pressure; Lindemann electrometers controlled by a Weston normal cell were employed. The results are shown in Fig. 1. By multiplying the ordinates of the lower nitrogen curve by the relative density of the gases, $3 \cdot 06$, one obtains points corresponding to the krypton curve. With radium $\mathrm{C}$ gamma rays $I_{\mathrm{Kr}} / I_{N_{2}}$ was found to be $5 \cdot 3$, which value differs widely from that for cosmic rays.

We would emphasize once more that neither in this flight nor in the flights of March 29, $1936^{2}$ and June 18, 1936 did we find discontinuities such as those found by G. A. Suckstorff ${ }^{3}$ and more recently by J. Juilfs ${ }^{4}$. This is why it seems to us difficult to admit the existence in the atmosphere of radioactive

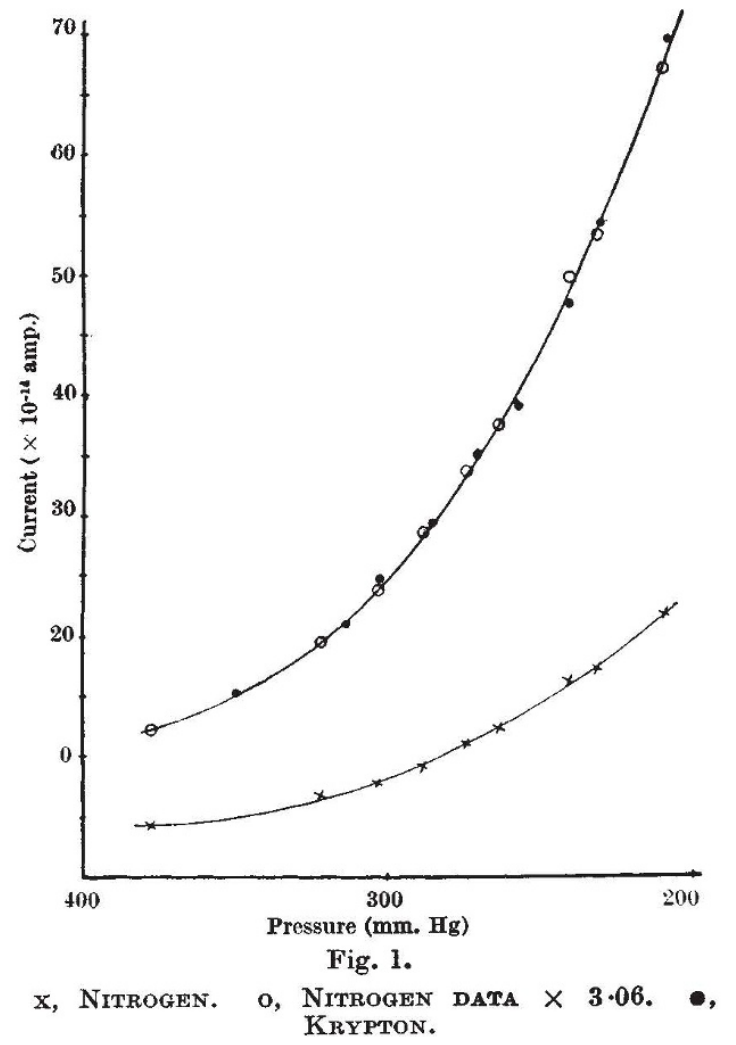

substances of extra-terrestrial origin. Not only are our curves continuous, the curve of computed mass absorption coefficients is quite smooth (Fig. 2), without any maxima, contrary to the results of W. Kolhörster ${ }^{5}$. Our curves are much steeper than those of Kolhörster.
The residual currents of the ionization chambers were checked by us in a rock-salt mine $406 \mathrm{~m}$. deep at Wapno (Province of Poznań). This rock-salt mine is absolutely dry, almost free from potassium salts, and has a constant temperature of about $26^{\circ} \mathrm{C}$. One of the ionization chambers was filled with argon at a

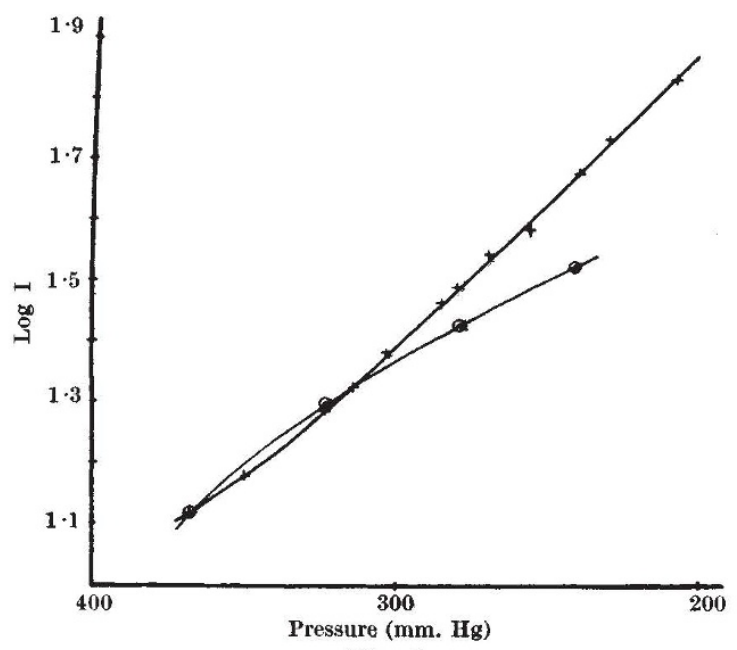

Fig. 2.

o, Kolhörster's data; $x$, PReshent aUthors' data

pressure of $30 \mathrm{~atm}$. It showed a residual current of about $1 / 320$ of the value measured at earth surface. Thus we had at a depth equivalent to $900 \mathrm{~m}$. of water a current of the same order of magnitude as that found by $J$. Clay at the deepest point $(270 \mathrm{~m}$.) he reached in the Gulf of Aden. Our residual currents showed remarkably large irregular fluctuations; thus we think the anomalies found at great depths by J. Clay, as also those of A. C. Corlin 7 , are not due to cosmic rays but to fluctuations of the residual currents. The accidental character of these abnormalities is best seen from inspection of the ionization curves, the rapid decrease of Clay's curve at $270 \mathrm{~m}$. being absent on the curve of Corlin.

More detailed data concerning this work will be found in the paper which will appear shortly in the Acta Physica Polonica. All expenses connected with the observations were covered by the Committee of the First Polish Stratosphere Balloon Flight. Some apparatus was acquired, thanks to a grant obtained by one of us (S. Z.) from the Ministry of Education and the Mianowski Foundation.
S. Szczeniowski.
S. ZiemeCKI.
K. NARKIEWICZ-JoDKo.

Institute of Theoretical Physics, University,
Wilno.

Physical Laboratory,

Main School of Agriculture, Warsaw. June 4.

1 Juilfs, J., and Masuch, V., Z. Phys., 104, 458 (1937).

Ziemecki, S., and Narkiewicz-Jodko, K., NATURE, 137, 944 (1936). s Suckstorff, G. A., Phys, Z., 35, 368 (1934).

4 Juilfs, J., Phys. Z., 38, 691 (1937).

5 Kolhörster, W., and Tuwim, L., "Ergebnisse d. Kosm. Physik", 1 151 (Leipzig, 1931).

- Clay, J., Physica, 1, 373 (1934).

${ }^{7}$ Corlin, A., Nature, 133, 63 (1934). 